PHYSICAL REVIEW E 96, 069901(E) (2017)

\title{
Publisher's Note: Constant-pressure nested sampling with atomistic dynamics [Phys. Rev. E 96, 043311 (2017)]
}

\author{
Robert J. N. Baldock, Noam Bernstein, K. Michael Salerno, Lívia B. Pártay, and Gábor Csányi
}

(Received 30 November 2017; published 6 December 2017)

DOI: 10.1103/PhysRevE.96.069901

This paper was published online on 30 October 2017 with an incorrect reference. Reference [15] should read as "[15] Originally from https://atomistics.osu.edu/eam-potential-generator/index.php, also available from the Supplemental Material [13]." The reference has been corrected as of 28 November 2017. The reference is incomplete in the printed version of the journal. 